Chem. Pharm. Bull.

29 (3) $844-848(1981)$

\title{
The Preparation of Mitomycin C, Adriamycin and Daunomycin Covalently Bound to Antibodies as Improved Cancer Chemotherapeutic Agents
}

\author{
Toshio Suzuki, Etsuko Sato, Kozo Goto, Yuko Katsurada, \\ Katsuo Unno,* and Toshio TaKahashi \\ Department of Pharmacy, Akita University Hospital and Department of Surgery, \\ Akita University School of Medicine, Hondo, Akita 010, Japan
}

(Received September 16, 1980)

\begin{abstract}
Mitomycin $\mathrm{C}$, daunomycin and adriamycin, three potent aancer chemotherapeutic agents, were linked to immunoglobulins by the cyanogen bromide method and the conjugates were separated on Sepharose 6B. The most suitable conditions for binding of the drug to the antibody, while retaining both antibody and drug activity, included the use of $25-50 \mathrm{~mol}$ of cyanogen bromide per mol of IgG at pH 11 for the activation of immunoglobulin.

The extent of substitution in this preparation was about $1 \mathrm{~mol}$ of drug per mol of IgG. This conjugate might be considered as a sustained release form of the antitumor agent.

Keywords- - mitomycin C; daunomycin; adriamycin; cyanogen bromide method; anti- $\alpha$-fetoprotein; time course; drug activity; antibody activity; cancer chemotherapy
\end{abstract}

Much recent work in clinical cancer chemotherapy has been aimed at developing methods to enhance the effects of antitumor agents that are currently available. One possible approach for increasing the effectiveness of antitumor drugs would be to find methods of altering their distribution in the body to increase their local concentration at the tumor cell sites. In this way, the selectivity of their toxicity for the tumor cells might be enhanced.

With the development of tumor immunology, many investigators ${ }^{\mathrm{I}}$ have sought to use antibodies to antigenic determinants expressed preferentially on tumor cells as carriers of cytotoxic agents. For this approach to succeed, both the antibody and the cytotoxic agent must retain activity when the two are linked together, or alternatively they may be linked in a manner allowing the release of the active agent after reaching the target cell.

Several reports ${ }^{2}$ have appeared in which complexes of alkylating drugs with immunoglobulins and other macromolecules have been described. Recently, Hurwitz et al. ${ }^{3}$ linked daunomycin (2) and adriamycin (3), two potent cancer chemotherapeutic agents, to immunoglobulins by the periodate oxidation method to give conjugates which retained both drug and antibody activity. However, this procedure could not be applied to mitomycin C (1)

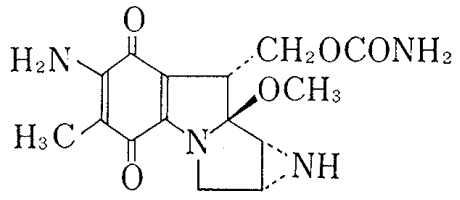

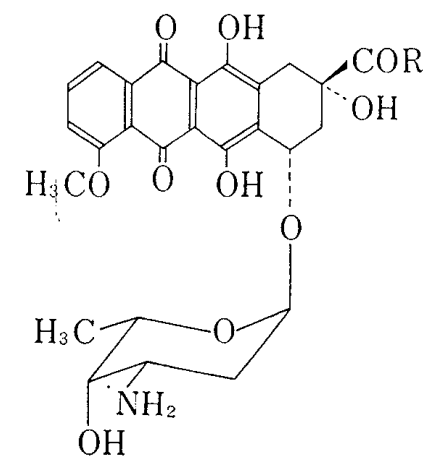

$2: \mathrm{R}=\mathrm{CH}_{3} \quad:$ daunomycin

$3: \mathrm{R}=\mathrm{CH}_{2} \mathrm{OH}:$ adriamycin

Fig. 1. The Structures of Mitomycin C, Daunomycin and Adriamycin 
and related compounds, which are relatively inexpensive compared to daunomycin (2) and adriamycin (3), since these compounds contain no $\alpha$ - aminohydroxy group or glycol moiety in their molecules.

In the present study, we have used mitomycin C (1), daunomycin (2) and adriamycin (3) as antitumor antibiotics and antibody of bovine serum albumin (BSA) as a model system or antibody of $\alpha$-fetoprotein (AFP) as a carcinofetal antigen. We have found conditions under which the drugs can be covalently linked to antibodies, preserving both the antibody activity and the pharmacological activity of the bound drugs.

\section{Experimental}

Drugs-Mitomycin C (1), daunomycin (2) and adriamycin (3) were from Kyowa Hakko Co., Ltd. Sepharose 6B was purchased from Pharmacia Fine Chemicals Co. (Sweden). Other chemicals used were of reagent grade quality, and were purchased from Wako Chemicals Co., Ltd.

Antisera- - Antiserum to BSA was produced in rabbits by weekly s.c. injections of $1 \mathrm{mg}$ of BSA emulsified in Freund's complete adjuvant. The immunoglobulin fraction of the antiserum was prepared by precipitation with ammonium sulfate at $33 \%$ saturation, followed by chromatography on DEAE-cellulose with $0.01 \mathrm{~m}$ phosphate buffer ( $\mathrm{pH} 8.0$ ) as an eluant.

Rabbit antiserum to rat AFP4,5) was prepared by p.o. injections of $500 \mu \mathrm{g}$ of rat AFP at 2-week intervals. Antibodies against AFP was purified by affinity chromatography, with $8 \mathrm{~m}$ urea as an eluant.

Preparations of Drug-IgG Conjugates-Drug-IgG conjugates were prepared by modifying the method of Axén et al.6) Treatment of IgG with cyanogen bromide would result in the formation of imidocarbonates, which are responsible for most of the coupling with the amino groups of the drugs, as shown in Fig. 2.

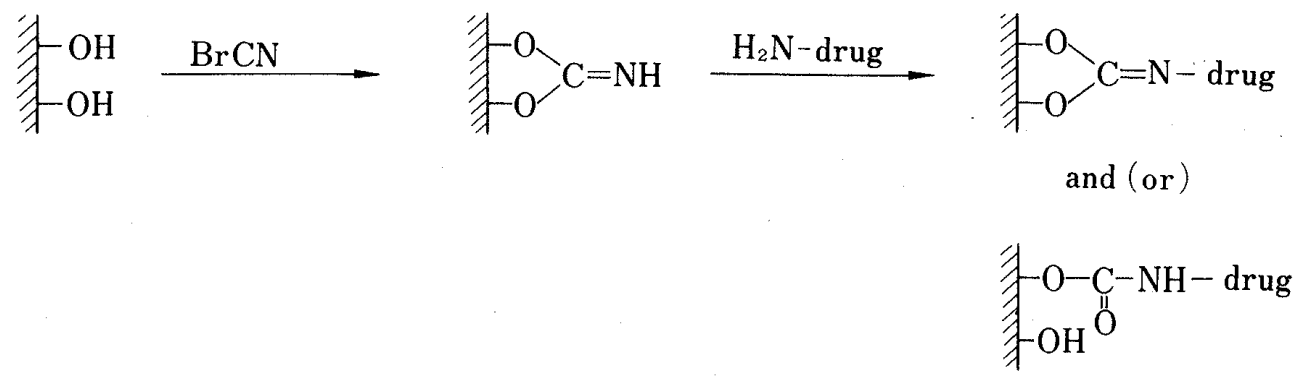

Fig. 2. Chemical Activation of IgG with Cyanogen Bromide and Chemical

Coupling of Drugs with Cyanogen Bromide-Activated IgG

The amount of cyanogen bromide indicated in Table II was added to a stirred solution of $20 \mathrm{mg}$ of IgG in $2 \mathrm{ml}$ of water in several portions at intervals of a couple of minutes, and the $\mathrm{pH}$ of the mixture was maintained at 11 by addition of $0.5 \mathrm{~N}$ sodium hydroxide solution during that time. Stirring was continued for $10 \mathrm{~min}$ at room temperature, then the $\mathrm{pH}$ of the mixture was adjusted by adding $5 \%$ of acetic acid solution (in which the drugs were stable) (mitomycin $\mathrm{C}, \mathrm{pH}=7.5$; daunomycin, $\mathrm{pH}=6.5$; adriamycin, $\mathrm{pH}=5.5$ ), and a solution of drug $(2 \mathrm{mg})$ in $2 \mathrm{ml}$ of water was added. The mixture was stirred for an additional $24 \mathrm{hr}$ in the dark under nitrogen at room temperature. The products were separated by gel filtration on Sepharose $6 \mathrm{~B}$ at $4^{\circ}$ with $\mathrm{PBS}^{7}$ ) as an eluant. The product was concentrated and washed with water by ultrafiltration (PM; cut-off level, 30000; Amicon Far East Ltd.).

Analytical Method-The degree of substiution was determined spectrophotometrically by assuming that mitomycin $\mathrm{C}$ has absorbance with $\lambda_{\max }=363 \mathrm{~nm}, E_{1 \mathrm{~cm}}^{1 \%}=623$, daunomycin and adriamycin have absorbance with $\lambda_{\max }=495 \mathrm{~nm}, E_{1 \mathrm{~cm}}^{1 \%}=206$, and $\lambda_{\max }=495 \mathrm{~nm}, E_{1 \mathrm{~cm}}^{1 \%}=196$, respectively, and IgG has absorbance with $\lambda_{\max }=280 \mathrm{~nm}, E_{1}^{1 \%}=13.5$.

The degree of substitution was calculated as follows: degree of substitution $=$ mol concentration of drug contained in conjugates/mol concentration of antibody contained in conjugates.

The antimicrobial activity was determined by the disc-plate method, with Bacillus subtilis ATCC 6633 as a test microorganism.

The antibody activity was measured by the radial immunodiffusion method or Ouchterlony method.

\section{Results and Discussion}

\section{Drug Binding}

Mitomycin $\mathrm{C}$ was bound to immunoglobulin by the cyanogen bromide method. Fig. 3 
a)

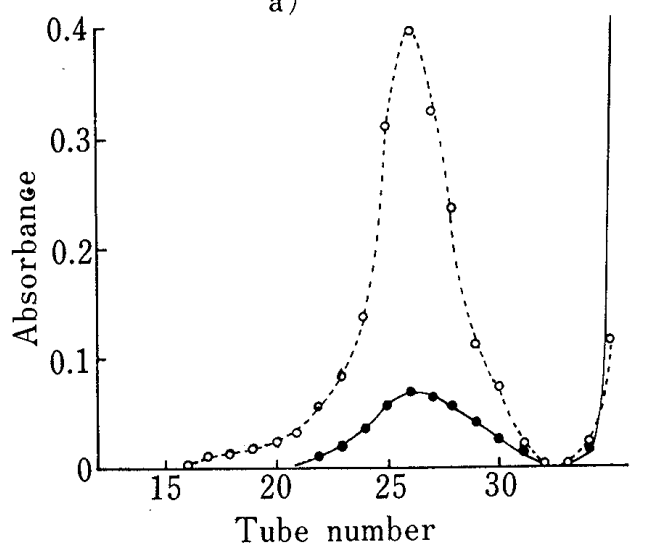

b)

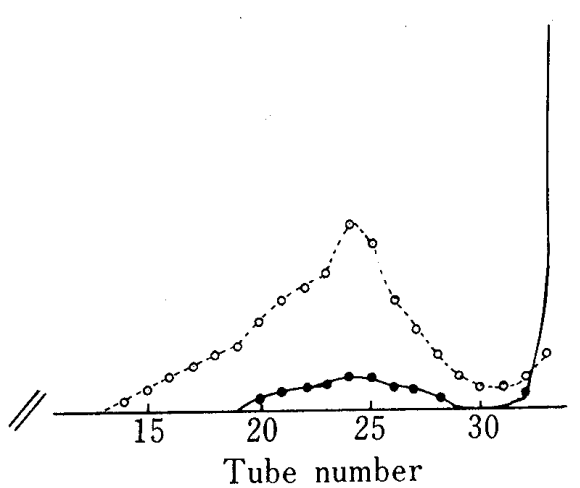

Fig. 3. Separation of Free from Bound Mitomycin C

Gel filtration on Sepharose 6B. Column dimensions, $2.64 \times 45 \mathrm{~cm}$. Buffer, $0.067 \times$ phosphate $(\mathrm{pH} 7.2)+0.15 \mathrm{~m} \mathrm{NaCl}$. Flow rate, $20 \mathrm{ml} / \mathrm{hr}$. Fraction volume, $5 \mathrm{ml}$.

absorbance at $280 \mathrm{~nm}$, absorbance at $363 \mathrm{~nm}$.

a) Anti-BSA $18.7 \mathrm{mg}$, BrCN $0.66 \mathrm{mg}$ (50 mol per $\mathrm{mol} \mathrm{IgG}$ ), MMC $2 \mathrm{mg}$.

b) Anti-AFP $14.3 \mathrm{mg}$, BrCN $0.51 \mathrm{mg}(50 \mathrm{~mol}$ per mol IgG), MMC $1.4 \mathrm{mg}$.

shows the separation of bound from free drug by gel filtration on Sepharose 6B. The covalently bound mitomycin $C$ appeared in the exclusion volume (in the case of Fig. 3a, tubes 23-30; in that of Fig. 3b, tubes $21-28$ ) of the column. The extent of substitution in this preparation was about $1 \mathrm{~mol}$ of drug per mol of IgG.

\section{Effect of Amount of Cyanogen Bromide and $\mathrm{pH}$ on Antibody Activity}

As a preliminary test, we attemted to prepare the conjugate according to the method of Axén et al. ${ }^{6}$ ) Thus, IgG was activated with a large excess of cyanogen bromide, 2800 or $1400 \mathrm{~mol}$ per $\mathrm{mol}$ of IgG at $\mathrm{pH} 11$. It was found that the conjugate retained drug activity but had no antibody activity (Table II). There are presumably two factors which would affect the antibody activity when the antibody is activated, one of them being the amount of cyanogen bromide and the other, $\mathrm{pH}$. Therefore antibody activity was examined under various conditions, as shown in Table I. As can be seen, it was found that there was no effect on antibody activity from $\mathrm{pH} 9$ to 11 , but antibody activity was decreased as the amount of cyanogen bromide was increased, and also by quenching of the reaction by amino acids such as glycine. It is known that a greater quantity of ligand is incorporated as the $\mathrm{pH}$ is increased

TABLE I. Effects of Cyanogen Bromide and $\mathrm{pH}$ on Antibody Activity

\begin{tabular}{|c|c|c|c|}
\hline \multirow{2}{*}{$\begin{array}{c}\text { Amount of } \mathrm{BrCN} \\
\text { Molar ratio } \\
(\mathrm{BrCN} / \mathrm{lgG})\end{array}$} & \multicolumn{3}{|c|}{ Antibody activity $(\mathrm{pH})$} \\
\hline & 11 & 10 & 9 \\
\hline 0 & H & Ht & $H$ \\
\hline 3 & H & \# & H \\
\hline 12 & $H$ & 世 & H \\
\hline 24 & $H$ & H & H \\
\hline 40 & H & & \\
\hline 50 & H & & \\
\hline 60 & + & & \\
\hline 80 & + & & \\
\hline 100 & - & & \\
\hline $50+$ glycine $(50 \mathrm{~mol} / \mathrm{IgG} \mathrm{mol})$ & + & + & + \\
\hline
\end{tabular}

Antibody activity was measured by the Ouchterlony method. In this table, Ht represents retention, \# represents moderate retention, + represents slight retention, and - represents no retention of the antibody activity. 
during activation. As a result of these experiments, $25-50 \mathrm{~mol}$ of cyanogen bromide per $\mathrm{mol}$ of $\mathrm{IgG}$ and $\mathrm{pH} 11$ were selected as standard conditions for the activation of antibody.

Since Axén and Ernback ${ }^{6}$ ) reported that the reaction between polysaccharides and cyanogen bromide gave activated polysaccharide which could be coupled with amine, this cyanogen bromide procedure has been widely used for the preparation of insolublized molecules as affinity chromatographic adsorbents or for the preparation of sustained release derivatives. such as mitomycin C-agarose bead conjugate and mitomycin C-dextran conjugate.

The present study was undertaken to determine whether or not this procedure could be applied to relatively unstable antibody instead of polysaccharide. To our knowledge, no previous work has been done on this problem.

It is known that the Fc fragment of IgG molecules contains sugar, so we attempted to activate the hydroxy group of the sugar with cyanogen bromide. It was found that antibody activity was entirely lost when a large excess of cyanogen bromide $(1400-2800 \mathrm{~mol}$ per mol IgG) was used for activation. Antibody activity was also lost when an amino acid such as glycine was added to the mixture in order to quench the coupling reaction. This result can be explained as follows: Fab fragment of IgG having antibody activity was also activated by cyanogen bromide to form an imidocarbonate which reacted easily with the amino acid. (such as glycine) rather than the drugs. Without addition of amino acid, the imidocarbonate, an unstable intermediate, was gradually hydrolyzed and reverted to the starting glycohol or amino alcohol.

The preparation of the conjugate was achieved by activation of the antibody with cyanogen bromide followed by coupling with an amine. We first investigated the effect of $\mathrm{pH}$ and the amount of cyanogen bromide in the activation step.

Table II shows that mitomycin $C$-antibody conjugate which retains both antibody and drug activity was obtained by using $25-50 \mathrm{~mol}$ of cyanogen bromide to $1 \mathrm{~mol}$ of antibody. This amount of cyanogen bromide had no effect on the recovery of antibody, the extent of substitution or the drug activity. An addition of $\beta$-cycladextrin $(\beta$-CD) or sucrose, which has many hydroxy groups, to the mixture decreased the recovery of IgG, drug activity and antibody activity.

Daunomycin and adriamycin, both having an amino function in the molecule, were also coupled with anti-BSA to give conjugates under the conditions described above. The degree of substitution, drug activity and antibody activity of the conjugates were about 1, $10 \%$. and $30 \%$, respectively.

TABLE II. Conditions of the Chemical Fixation of Drugs with Antibody, Recovery and Properties of the Conjugates

\begin{tabular}{|c|c|c|c|c|c|}
\hline Drug-IgG conjugates & $\begin{array}{l}\text { Amount of } \\
\text { BrCN } \\
\text { Molar ratio } \\
\text { (BrCN/IgG) }\end{array}$ & $\begin{array}{l}\text { IgG } \\
\text { recovery } \\
(\%)\end{array}$ & $\begin{array}{l}\text { The degree of } \\
\text { substitution } a) \\
\text { (drug mol/ } \\
\text { IgG mol) }\end{array}$ & $\begin{array}{c}\text { Drug } \\
\text { activity } \\
(\%)\end{array}$ & $\begin{array}{c}\text { Antibody } \\
\text { activityc) }^{(\%)}\end{array}$ \\
\hline MMC-Normal IgG & 2800 & 75.5 & 1.0 & 11.3 & - \\
\hline MMC-Normal IgG & 1400 & 74.0 & 1.2 & 19.9 & - \\
\hline MMC-Anti-BSA & 2800 & 61.8 & 1.1 & 23.4 & 0 \\
\hline MMC-Anti-BSA & 50 & 58.3 & 1.0 & 53.5 & 96 \\
\hline MMC-Anti-BSA & 25 & 65.9 & 1.0 & 34.2 & 60 \\
\hline MMC-Anti-BSA- $\beta$-CD & 280 & 31.6 & 1.2 & 28.2 & 64 \\
\hline MMC-Anti-BSA-Sucrose & 280 & 26.0 & 1.1 & 15.8 & 61 \\
\hline Daunomycin-Anti-BSA & 50 & 55.5 & 1.2 & 10.9 & 30 \\
\hline Adriamycin-Anti-BSA & 50 & 35.0 & 1.6 & 13.5 & 34 \\
\hline MMC-Anti-AFP & 50 & 60.1 & 1.1 & 25.7 & 49 \\
\hline
\end{tabular}

a) The degree of substitution was determined spectrometrically.

b) Drug activity $=\frac{\text { Drug concentration found by bioassay }}{\text { Drug concentration found spectrometrically }} \times 100$.

c) Antibody activity was determined by the radial immunodiffusion method. 


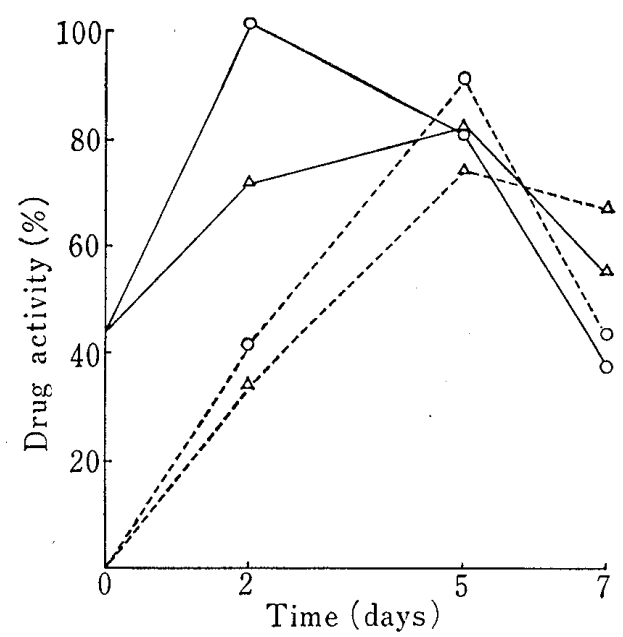

Fig. 4. Time Course of Drug Activity MMC-Normal IgG conjugate was dissolved in water and stored at $37^{\circ}(O)$ or $4^{\circ}(\triangle)$. - - Drug activity of the filtrate after ultrafiltration of MMC-Normal IgG conjugate. - Drug activity of the solution without ultrafiltration. Drug activity was determined by bioassay.
Since a preliminary test was successful, antibody of AFP (which has been utilized for the diagnosis of hepatoma and yolk sac tumor) was chosen as a tumor-specific antibady and the mitomycin C-conjugate was synthesized according to the method described above.

Table II shows that the extent of substitution and recovery of antibody with anti-AFPconjugate were almost the same as those with anti-BSA. On the other hand, the drug and antibody activities of anti-AFP-conjugate were almost half of those of anti-BSA.

As can be seen in Fig. 4, this conjugate might be suitable as a sustained release form of the anticancer agent, since the drug activity of the conjugate increased with time. This result can be explained in terms of drug release via hydrolysis and aminolysis, as described recently by Sezaki et al. ${ }^{8,9)}$

Although our method is potentially useful in cancer chemotherapy, several problems still remain in connection with the binding of therapeutically effective amounts of antitumor agents, and the avoidance of host reactions to foreign proteins.

Thus, we developed a synthetic method for conjugates of mitomycin $\mathrm{C}$, daunomycin and adriamycin with immunoglobulins. This procedure should be suitable for preparing conjugates of various drugs having an amino function in their molecules with immunoglobulins.

\section{References and Notes}

1) For a recent review, see T. Ghose and A.H. Blair, J. Natl. Cancer Inst., 61, 657 (1978) and references cited therein.

2) D.A.L. Davies and G.J. O'Neill, Brit. J. Cancer, 28, 285 (1973); I. Flechner, European J. Cancer, 9, 741 (1973); T. Ghose and S.P. Nigam, Cancer, 29, 1398 (1972); T. Ghose, S.T. Norvell, A. Guclu, D. Cameron, A. Bodurtha, and A.S. Macdonald, Brit. Med. J., 3, 495 (1972); J.H. Linford, G. Froese, I. Berczi, and L.G. Israels, J. Natl. Cancer Inst., 52, 1665 (1974); M. Szekerke, R. Wada, and M.E. Whisson, Neoplasma, 19, 211 (1972).

3) E. Hurwitz, R. Levy, R. Maron, M. Wilchek, R. Arnon, and M. Sela, Cancer Res., 35, 1175 (1975).

4) S. Nishi and H. Hirai, Biochim. Biophys. Acta, 278, 293 (1972).

5) S. Nishi, H. Watabe, and H. Hirai, J. Immunol., 109, 957 (1972).

6) R. Axén and S. Ernback, Eur. J. Biochem., 18, 351 (1971).

7) Abbreviations used: PBS, $0.15 \mathrm{M} \mathrm{NaCl}$ and $0.067 \mathrm{~m}$ phosphate, $\mathrm{pH} 7.2$; AFP, $\alpha$-fetoprotein; BSA, bovine serum albumin; MMC, mitomycin $\mathrm{C} ; \beta$ - $\mathrm{CD}, \beta$-cyclodextrin.

8) T. Kojima, M. Hayashida, S. Muranishi, and H. Sezaki, Chem. Pharm. Bull., 26, 1818 (1978).

9) Idem, J. Pharm. Pharmacol., 32, 30 (1980). 